\title{
Performance of Postgraduate students in Objective Structured Practical Examination (OSPE) in the Speciality of Obstetrics and Gynaecology
}

\author{
S ROUF ${ }^{\mathrm{a}}$, A MAJID
}

Summary:

Objectives: The aim of the study was to evaluate the performance of the postgraduate students in Objective Structured Practical Examination (OSPE) in the speciality of Obstetrics and Gynaecology. This new trend of assessment was implemented first time in Bangladesh as a part of clinical assessment in the Fellowship examination.

Materials and Methods: Three Mock OSPE were arranged for the postgraduate students before appearing in the final Fellowship examination by the faculty of Obstetrics and Gynaecology along with Bangladesh College of Physicians and Surgeons (BCPS) in the month of September and November 2005. A total of 109 students participated. In OSPE, students rotate through different stations where they are asked to perform certain tasks. In each circuit three different categories of stations were arranged, procedural stations for demonstrating certain skills, interactive stations with simulated patients for patient education, counseling and history taking and question stations where specimens, instruments, data and scenarios were placed for evaluation of interpretation, decision

\section{Introduction}

In the field of medical education, new trends are emerging in teaching and learning as well as in assessment of students. The latter is a matter of continuing concern for medical teachers specially the assessment of clinical competencies. ${ }^{1}$ The clinical examinations is regarded by many examiners as of key importance in the assessment of students' competence to practice medicine and is the corner

a. Dr. Salma Rouf, Assistant Professor of Obstetrics and Gynaecology, Department of Obstetrics and Gynaecology, Dhaka Medical College Hospital

b. Prof. Ameena Majid, Professor of Obstetrics and Gynaecology, Department of Obstetrics and Gynaecology, Dhaka Medical College Hospital

Address of correspondent: Dr. Salma Rouf, Assistant Professor of Obstetrics and Gynaecology, Department of Obstetrics and Gynaecology, Dhaka Medical College Hospital.

Received: 21 March, 2006

Accepted: 24 July, 2006 making and problem solving skills. For the procedural and interactive stations a preformed standardized checklist was placed with an observer for evaluation. For the question stations answer keys were prepared for checking. Pass mark was set at $52 \%$ (13 grade) as decided by the Examination Committee of BCPS.

Results: Fifty six (51.38\%) students scored $52 \%$ or above and declared as having passed. Performance in the procedural station was very poor in the first Mock $(40.20 \%$ success rate) but the results got better in the subsequent Mock (52\% in Mock II and 72\% in Mock III). Performance in the interactive stations was not at all satisfactory, 75\% could not achieve the desired credit revealing the fact that the students were very poor in communication skills. Performance in the question stations was variable depending upon the objective and task enrolled.

Conclusions: OSPE is objective, structured, reliable and valid way to assess all the component of clinical competency and is an option to improve quality of clinical assessment, teaching and learning.

(J Bangladesh Coll Phys Surg 2007; 25 : 3-8)

stone in qualifying examination. ${ }^{2,3}$ The concept of assessment has changed from "testing for certification purpose" towards "assessment outcomes" and the use of results of assessment in the valid and reliable way. More emphasis is now being placed on the learning outcomes and its integration with the curriculum. Students are now required to possess a breadth of skills - abilities, adaptabilities, problem solving talents, creativity and communication skills - all the necessary competencies to be a professional.

Assessment will have powerful effect on what students learn and how they go about their studies. ${ }^{4,5}$ If the assessment methods are inappropriate, there may be unfortunate consequence on the learning undertaken and for the curriculum. ${ }^{6}$ This concept makes assessment a real concern for medical teachers. Assessment should encourage learning. 
Deficiencies in the conventional or traditional clinical examination - 'long and short case viva approach' have bean clearly identified. ${ }^{7}$ Traditional form of assessment is "norm referenced" where more emphasis is given on comparison between students rather than individual achievements. Curriculum content and learning outcomes are too often not reflected and only a limited number of areas of a course can be tested. Candidates are tested on different cases of different difficulties and judged by different standards by different examiners. So validity and reliability of the results are often questionable. $8,9,10$

In order to overcome the poor reliability and dissatisfaction of the traditional method OSCE/OSPE (objective structured clinical/practical examination) a flexible examination structure was first described by Harden and his colleagues. ${ }^{2}$

To keep pace with the advancement in medical education, in Bangladesh, it is now recommended to implement OSCE/OSPE as a part of clinical examination both in undergraduate as well as in Postgraduate Fellowship examination for all speciality.

Bangladesh College of Physicians and Surgeons (BCPS) has been conducting the Fellowship examination of different faculties. As this trend of assessment is a new approach in Bangladesh, BCPS and different faculties decided to conduct mock tests for the postgraduate students before implementing it in the final FCPS Part-II examination of January, 2006.

Faculty of Obstetrics and Gynaecology conducted three mock tests for the students and the performance of students were analysed on three different categories of stations - procedural, interactive and question stations.

\section{Materials and Methods}

Three mock OSPE were arranged by the faculty of Obstetrics and Gynaecology along with the technical cooperation of BCPS during the month of September 2005 and November 2005. The aim of those mock tests was to expose and orient the students (FCPS Part-II candidates) regarding this new trend of assessment going to be implemented in the final Part Fellowship examination. A total of 109 students participated (out of 120 enrollment) in the three mock trial (34 in mock I, 36 in mock II and 39 in mock III). On each day four circuits were arranged for a total of 40 students. In each circuit 10 students were enrolled serially to rotate through 12 stations including 2 rest stations. In each station a student was asked to do certain task and 5 minutes time was allocated for each student. One hour time was spent for completion of each circuit and half an hour time was allowed for script checking and station resetting in between the circuit. In each circuit 12 stations were arranged in the following way - three procedural stations for demonstrating clinical skills, two interactive stations with simulated patients for patient education, counselling and history taking. There were five question stations where specimens, instruments, data (cardiotocography, partograph, antenatal records) and scenarios were placed for evaluation of interpretation, decision making and problem solving skills. Different sets of questions were given for the three mock tests.

\section{Evaluation}

For the procedural and interactive stations a preformed standardized check list was placed with an observer. For the question stations answer keys were prepared for checking after completion of each circuit. For each station 10 marks were allocated and a total of 100 for 10 stations. Pass marks was set at $52 \%$ (13 grade) as decided by the examination committee of BCPS.

\section{Results}

A total 109 students appeared in the examination out of 120 enrollment among which 56 (51.38\%) students scored 52\% (13 grade) or above and declared as having passed. The remaining 53 (48.62\%) students scored below 52\% and did not achieve the desired credit (13 grade). On average success rate was almost $50 \%$ as described in table 1 .

Analysis of the performance in the procedural stations was discussed in table 2 and revealed the following facts. In mock I, performance was not at all satisfactory, only $40.20 \%$ achieved the satisfactory credit. Subsequently the results got better in the subsequent mock and the success rate rose from almost $52 \%$ in the 2nd mock to $72 \%$ in the $3^{\text {rd }}$ mock respectively.

Analysis of the interactive stations revealed (table-3) very poor performance in counselling stations, more 
than $75 \%$ could not achieve the pass mark. Performance was slightly encouraging in history taking station. Overall performance in interactive station was poor and almost $60 \%$ did not achieve the satisfactory credit.

Performance in the question stations (table-4) was equivocal. More than $50 \%$ candidates succeeded.
Performance in station where CTG (Cardiotocography) was kept for interpretation was very unsatisfactory, only $22 \%$ candidate could achieve the desired credit.

Performance in one procedural station (table-5) used as control showed improvement of performance as the success rate rose from $38.24 \%$ in the $1^{\text {st }}$ mock to $74.36 \%$ in the $3^{\text {rd }}$ mock.

Table-I

\section{Performance of students in three MOCK test}

\begin{tabular}{|c|c|c|c|c|c|}
\hline & $\begin{array}{l}\text { Total no. of } \\
\text { students } 109\end{array}$ & $\begin{array}{c}\text { No. of } \\
\text { students } \\
\text { scored } \geq 52 \% \\
\left.\text { ( }{ }^{3} 13 \text { grade }\right)\end{array}$ & $\begin{array}{c}\text { No. of } \\
\text { students } \\
\text { scored }<52 \% \\
\text { ( }<13 \text { grade })\end{array}$ & $\begin{array}{l}\text { Total No. } \\
\text { succeeded }\end{array}$ & $\begin{array}{c}\text { Total No. } \\
\text { failed }\end{array}$ \\
\hline$\overline{\mathrm{MOCK}}$ & 34 & 10 & 24 & 56 & 53 \\
\hline MOCK II & 36 & 15 & 21 & $-51.38 \%$ & $-48.62 \%$ \\
\hline MOCK III & 39 & 31 & 8 & & \\
\hline
\end{tabular}

Table-II

\begin{tabular}{lcccccccc}
\multicolumn{10}{c}{ Performance in procedural stations } \\
& \multicolumn{10}{c}{ Procedural station 1 } & \multicolumn{2}{c}{ Procedural station 2 } & Procedural station 3 & Success & Failure \\
& $\geq 13$ grade & $<13$ grade & $\geq 13$ grade & $<13$ grade & $\geq 13$ grade & $<13$ grade & rate (\%) & rate (\%) \\
\hline MOCK I & 11 & 23 & 17 & 17 & 13 & 21 & 40.2 & 59.8 \\
n=34 & $32.35 \%$ & $67.65 \%$ & $50 \%$ & $50 \%$ & $38.24 \%$ & $61.76 \%$ & & \\
MOCK II & 25 & 11 & 19 & 17 & 12 & 24 & 51.85 & 48.15 \\
n=36 & $69.44 \%$ & $30.56 \%$ & $52.78 \%$ & $47.22 \%$ & $33.33 \%$ & $66.67 \%$ & & \\
MOCK III & 29 & 10 & 26 & 13 & 29 & 10 & 71.8 & 28.2 \\
n=39 & $74.36 \%$ & $25.64 \%$ & $66.67 \%$ & $33.33 \%$ & $74.36 \%$ & $25.64 \%$ & & \\
\hline
\end{tabular}

Table-III

\section{Performance in Interactive stations}

\begin{tabular}{lcccccc} 
& \multicolumn{2}{c}{$\begin{array}{l}\text { Interactive station } 1 \\
\text { C(Counselling) }\end{array}$} & \multicolumn{2}{c}{$\begin{array}{c}\text { Interactive station } 2 \\
\text { (History taking) }\end{array}$} & $\begin{array}{c}\text { Success } \\
\text { rate (\%) }\end{array}$ & $\begin{array}{c}\text { Failure } \\
\text { rate (\%) }\end{array}$ \\
& $\geq 13$ grade & $<13$ grade & $\geq 13$ grade & $<13$ grade & & \\
\hline MOCK I & 10 & 24 & 13 & 21 & 33.82 & 66.18 \\
n=34 & $29.41 \%$ & $70.59 \%$ & $38.24 \%$ & $61.76 \%$ & & \\
MOCK II & 9 & 27 & 25 & 11 & 47.22 & 52.78 \\
n=36 & $25 \%$ & $75 \%$ & $69.44 \%$ & $30.56 \%$ & & \\
MOCK III & 8 & 31 & 27 & 12 & 44.87 & 55.13 \\
n=39 & $20.51 \%$ & $79.49 \%$ & $69.23 \%$ & $30.77 \%$ & & \\
\hline
\end{tabular}




\section{Table-IV}

\begin{tabular}{|c|c|c|c|c|c|c|c|c|c|c|c|c|}
\hline \multicolumn{13}{|c|}{ Performance in question stations } \\
\hline \multirow[t]{2}{*}{ Ques Stat 1} & \multirow[b]{2}{*}{$\begin{array}{l}\geq 13 \\
\text { grade }\end{array}$} & \multirow[b]{2}{*}{$\begin{array}{l}<13 \\
\text { grade }\end{array}$} & \multicolumn{2}{|c|}{ Ques Stat 2} & \multicolumn{2}{|c|}{ Ques Stat 3} & \multicolumn{2}{|c|}{ Ques Stat 4} & \multicolumn{2}{|c|}{$\begin{array}{l}\text { Ques Stat } 5 \\
\text { (CTG) }\end{array}$} & \multirow[t]{2}{*}{$\begin{array}{l}\text { Success } \\
\text { rate (\%) }\end{array}$} & \multirow[t]{2}{*}{$\begin{array}{l}\text { Failure } \\
\text { rate (\%) }\end{array}$} \\
\hline & & & $\begin{array}{l}\geq 13 \\
\text { grade }\end{array}$ & $\begin{array}{l}<13 \\
\text { grade }\end{array}$ & $\begin{array}{l}\geq 13 \\
\text { grade }\end{array}$ & $\begin{array}{l}<13 \\
\text { grade }\end{array}$ & $\begin{array}{l}\geq 13 \\
\text { grade }\end{array}$ & $\begin{array}{l}<13 \\
\text { grade }\end{array}$ & $\begin{array}{l}\geq 13 \\
\text { grade }\end{array}$ & $\begin{array}{l}<13 \\
\text { grade }\end{array}$ & & \\
\hline MOCK I & 15 & 19 & 21 & 13 & 15 & 19 & 25 & 9 & 6 & 28 & 48.24 & 51.76 \\
\hline$n=34$ & $44.12 \%$ & $55.88 \%$ & $61.76 \%$ & $38.24 \%$ & $44.12 \%$ & $55.88 \%$ & $73.53 \%$ & $26.47 \%$ & $17.65 \%$ & $82.35 \%$ & & \\
\hline MOCK II & 18 & 18 & 14 & 22 & 24 & 12 & 21 & 15 & 1 & 35 & 43.33 & 56.67 \\
\hline$n=36$ & $50 \%$ & $50 \%$ & $38.89 \%$ & $61.11 \%$ & $66.67 \%$ & $33.33 \%$ & $58.33 \%$ & $41.67 \%$ & $2.78 \%$ & $97.22 \%$ & & \\
\hline MOCK III & 28 & 11 & 18 & 21 & 28 & 11 & 30 & 9 & 18 & 21 & 62.56 & 37.44 \\
\hline $\mathrm{n}=39$ & $71.79 \%$ & $28.21 \%$ & $46.15 \%$ & $53.85 \%$ & $71.79 \%$ & $28.21 \%$ & $76.92 \%$ & 23.08 & $46.15 \%$ & $53.85 \%$ & & \\
\hline
\end{tabular}

Table-V

\begin{tabular}{|c|c|c|c|c|}
\hline \multicolumn{5}{|c|}{ Performance in procedural station used as control } \\
\hline & \multicolumn{2}{|c|}{ Performance } & \multirow[t]{2}{*}{ Success rate } & \multirow[t]{2}{*}{ Failure rate } \\
\hline & $\geq 13$ grade & $<13$ grade & & \\
\hline Mock I & 13 & 21 & $38.24 \%$ & $61.76 \%$ \\
\hline \multicolumn{5}{|l|}{$\mathrm{n}=34$} \\
\hline $\begin{array}{l}\text { Mock III } \\
\mathrm{n}=39\end{array}$ & 29 & 10 & $74.36 \%$ & $25.64 \%$ \\
\hline
\end{tabular}

\section{Discussion}

OSPE/OSCE is one of the options to improve the quality of clinical assessment. It is objective, structured, reliable and a valid way to assess all the components of clinical competency. It is beneficial for the students in terms of feedback given, providing the students a real idea to assess the strength and weakness of their own performance.

Before starting to analyze the performance of students at different stations, certain limitations of this study have to be mentioned. In this study three different batches of students appeared in three mock and were evaluated through different sets of stations. The homogenesity of the students' level of performance could be questioned. Although three different batches of students were evaluated in the same scale, all the students could be considered are at same level, as all of them fulfilled the enrolment criteria. They have all passed the Part-I FCPS, completed 2 years clinical training and one year postgraduate course. So homogenesity to a certain extent could be expected to have been maintained.

Use of three different sets of stations in three mocks were obligatory in order to avoid repetition and thereby question lickage. Although in all there mocks number of procedural, interactive and question stations were fixed. To achieve the homogenesity a common procedural station was used in mock I and III as a control station to evaluate and compare the performance.

Moreover performance in different stations were not compared to one another, rather comments were made on the overall performance of students in three different categories of stations.

In the procedural stations, students were asked to demonstrate certain procedures like - Forceps delivery, breech delivery, delivery of the placenta etc.

Analysis of the performance in the procedural stations, showed that the results were better in the 
succeeding mock and the success rate rose from $40 \%$ to $72 \%$. The reason behind this was probably the students got oriented with the procedural stations by receiving feedback after each mock and practiced accordingly to improve their skills. This again proved the fact that OSPE/OSCE actually encourage learning and motivate students for self directed learning for the better. Performance in the procedural stations also disclose some facts related to training. As there is no standardized protocol in the curriculum for learning skills, students are not oriented to practice skills according to check lists. So during demonstration they often missed certain steps and or chronology was not maintained. This also created confusion among the observer for marking the check lists. This realization urges the need for skill standardization and introduction of uniform protocol or learning guide for each procedure in the curriculum. This will ensure uniform skill based training and remove confusions among the trainees as well as the trainers.

Performance in the interactive stations specially in the counselling station has been very poor in all three mock, only to reveal the fact that poor attention has been paid in the cirriculum to practice communication skills. In traditional form of assessment (long case viva approach), this aspect of assessing communication skills is totally ignored. Besides, factual knowledge, history taking and counselling skills include many other important aspects such as correct phrasing of questions/statement, systematic approach, response followed, establishment of rapport, effective use of time etc. These aspects are not evaluated in long case viva approach by simply presenting a case.

Communication and interpersonal skill is an important but ignored aspect of clinical skill that has to be nurtured by the medical professionals. Feedback received from the performance in interactive stations will help the students to improve this skill and will also help the medical teachers to pay attention to this aspect during teaching.

Five questions stations were equipped with materials to evaluate different skills - data interpretation, problem solving, decision making skills etc. For example in one station an operated specimen was supplied and asked for identification, differential diagnosis, patient profile, treatment offered and the reason behind it, other modalities of treatment etc. So this station was designed to evaluate the reasoning skills of the students. Similarly in another station a drug was placed for identification and related questions were placed to know about its uses, indications, contraindications, advantages etc.

Another station was designed to evaluate the problem solving and decision making skills by placing a scenario where identification of patient's problem, differential diagnosis, investigation suggested and best option of treatment were asked chronologically in the form of patient management problem (PMP).

To evaluate the interpretation skills several data like antenatal records, partographs and CTG were placed.

Performance varied in question stations depending upon the objective and materials placed on that station. For example, a station, where a CTG (cardiotocography) was placed for interpretation, performance was very poor. This revealed the fact that majority of students were weak in CTG interpretation and need more practice in data interpretation skill. So OSPE helps to identify the group learning needs by detecting the major area of weakness.

A procedural station was repeated in mock I and mock III as a control station to evaluate the homogenesity of performance. In mock I, 38\% succeeded and the failure rate was $62 \%$. In Mock III performance was reversed with a success rate of $74 \%$. The possible explanation of this improvement is that after getting feedback from mock I, the students rectified their performance and practiced accordingly without being aware of the fact that the same station could be repeated, again proving the usefulness of OSCE as a method of providing feedback during a course. Another possibility might be the students enrolled in batch-III are of better quality than the previous one. This possibility could be nullified by previous discussion.

In the OSCE/OSPE the student's knowledge and skills are tested in compartments and the ability to look at the patient as a whole (holistic approach) is not tested. However, assessment of the student's competence need not be confined to the OSCE. To 
overcome this draw back OSCE can be combined with the more traditional type of long case, where the ability to handle a complete case can be assessed.

The time involved in setting up the examination is greater than for the traditional examination. With succeeding examination less time is required and both time and effort can be reduced if a bank of objective test items and check lists is maintained.

A properly designed OSCE should be based on a content blue print for each station. It is a criterion - referenced examination where a student has to reach a prescribed standard of competence to get a credit of success.

In conclusion OSCE/OSPE can be used in any situation where one has to assess a student's clinical competency. As with many educational advances the benefits are achieved by increased effort.

\section{References}

1. Newble D.I. ASME, Medical Education Booklet No.25. Assessing clinical competency at the undergraduate level. Association for the study of Medical Education. Dundee, Scotland, 1992.

2. Harden R.M and Gleeson F.A. ASME, Medical Education Booklet No.8. Assessment of medical competence using an objective structured clinical examination (OSCE). Medical Education, 1979, 13: 41-54.

3. Newfeld V.R and Norman G. R (eds). Assessing clinical competence. Springer New York, 1985.

4. Frederiksen N. The real test bias: influences of testing on teaching and learning. American Psychologist, 1984, 39: 193-202.

5. Newble D.I and Entwistle N.J. Learning style and approaches: implications for medical education. Medical Education, 1986, 20: 162-75.

6. Newble D.I and Jaeger K. The effect of assessments and examination on the learning of medical students. Medical Education, 1983, 17: 165-71.

7. Stokes J.F. The clinical examination (ASME), Medical Education Booklet No.2, Association for the study of Medical Education, Dundee, Scotland, 1974.

8. Newble D.I. The observed long case in clinical assessment Medical Education, 1991, 25: 369-73.

9. Newble D.I, Hoare J. and Elmslie R.G. The validity and reliability of a criterion - referenced examination of clinical competence. Medical Education, 1981, 15: 46-52.

10. Norman G.R, Vander Vleuten C.P.M and De Graaf E. Pitfaltls in the pursuit of objectivity: issues of validity, efficiency and acceptability. Medical Education, 1991, 25: $119-26$. 